\title{
REHABILITACION DEL TEATRO CENTRO DE NAVALCARNERO-MADRID/ESPAÑA
}

\author{
(REHABILITATION OF THE CENTRO THEATRE IN NAVALCARNERO-MADRID/SPAIN)
}

Miguel Verdú, Arquitecto

\section{RESUMEN}

En este artículo se describe la Rehabilitación de un pequeño teatro desde un punto de vista básicamente funcional. El teatro está situado en una ciudad de unos 9.000 habitantes próxima a Madrid; la obra de Rehabilitación se encuentra en su última fase. Se describen brevemente el entorno. caracteristicas y estado de conservación del edificio preexistente $y$, con mayor detalle, las intervenciones arquitectónicas llevadas a cabo en las distintas zonas funcionales del edificio (Caja de Escena, Sala, Vestibulos, Servicios del Público, Oficina, Camerinos, Locales Técnicos, Personal). Por último se pasa revista a los distintos capitulos del equipamiento teatral implantado (Protección contra Incendios, Mobiliario, Iluminación Escénica, Maquinaria Escénica, Equipo de Sonido, Vestido de Escenario, Proyección Cinematográfica y Equipamientos Varios). Talleres y Almacenes, Instalaciones Generales y Servicios del

\section{SUMMARY}

This article describes the renovation of a small Theatre considered essentially from a functional point of view. The theatre is located in a city of about 9.000 inhabitants near Madrid; the renovation work is now nearing its end. There is a brief description of the environment, characteristics and condition of the preexistent building, as well as a more detailed version of the architectural modifications carried out in the various functional areas of the building (Stage and Fly Tower, Auditorium, Foyers, Public Facilities, Office, Dressing Rooms, Technical Rooms, Workshops and Stores, General Installations and Artists and Technicians Facilities). Finally, the new theatre equipment (Fire Protection, Furniture, Stage Lighting, Stage Machinery, Sound Equipment, Stage Dress, Film Projection and Sundry Equipment) is reviewed.

\section{INTRODUCCION}

Se describe aqui la Rehabilitación del Teatro Centro de Navalcarnero, obra que se encuentra en estos momentos próxima a su finalización. Se ha tratado de dar a esta descripción un cierto detalle y un enfoque eminentemente funcional, considerando que este punto de vista puede ser el que tenga más interés, ya que el tamaño y presupuesto de la intervención son los de una obra modesta que no puede pretender resulta-

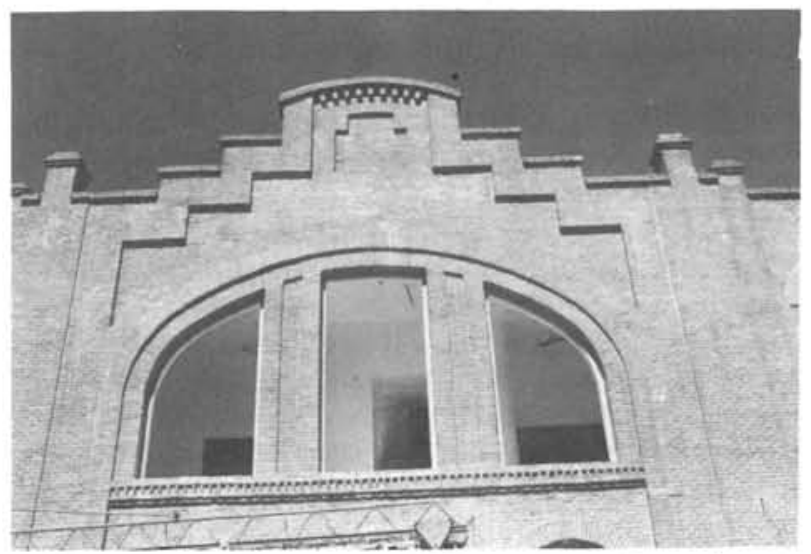

vista parcial de la fachada principal del Teatro Centro durante las obras de Rehabilitación. dos espectaculares (valga la expresión, un tanto paradójica tratándose de un teatro).

La politica de recuperación de teatros que actualmente está acometiendo la Administración Pública española en sus distintos niveles (Estado, Comunidades Autónomas y Ayuntamientos) ha reavivado el interés por los temas de Arquitectura Teatral y ha llevado a los tableros de los Arquitectos numerosos encargos de Rehabilitación de teatros, en la inmensá mayoria de los casos por primera vez (y probablemente por última). En mi experiencia como asesor del Ministerio de Cultura para temas de Arquitectura Teatral he podido comprobar cómo muchos Arquitectos "descubrian" el edificio teatral, volviendo a experimentar esa fascinación que históricamente ha producido el escenario como caja mágica o fábrica de lo imaginario.

El edificio teatral es una máquina para crear ilusión, y como toda máquina tiene sus reglas de funcionamiento; sus piezas deben cumplir bien su cometido y encajar perfectamente unas con otras. Estas reglas no son dificiles, pero hay que conocerlas para no cometer errores al diseñar o rehabilitar un teatro.

Sin embargo, para que haya teatro no es necesario un edificio. El teatro nació al aire libre, y a 


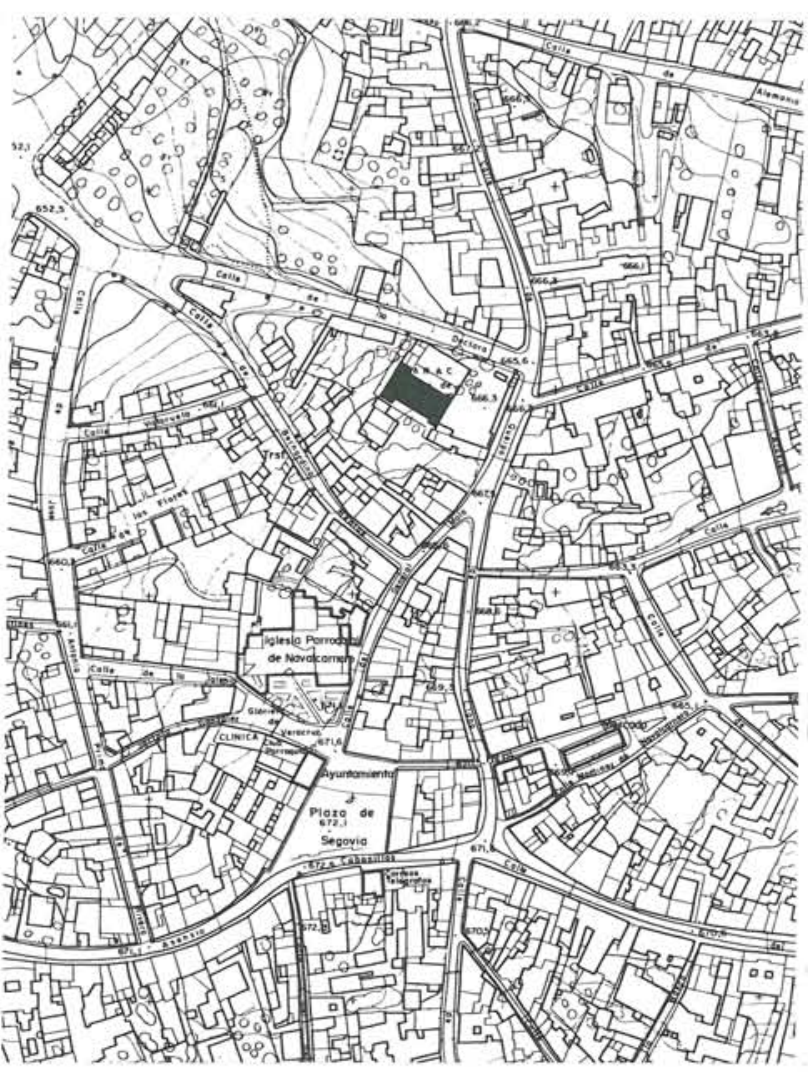

Plano de Navalcarnero con el Teatro Centro señalado en negro.

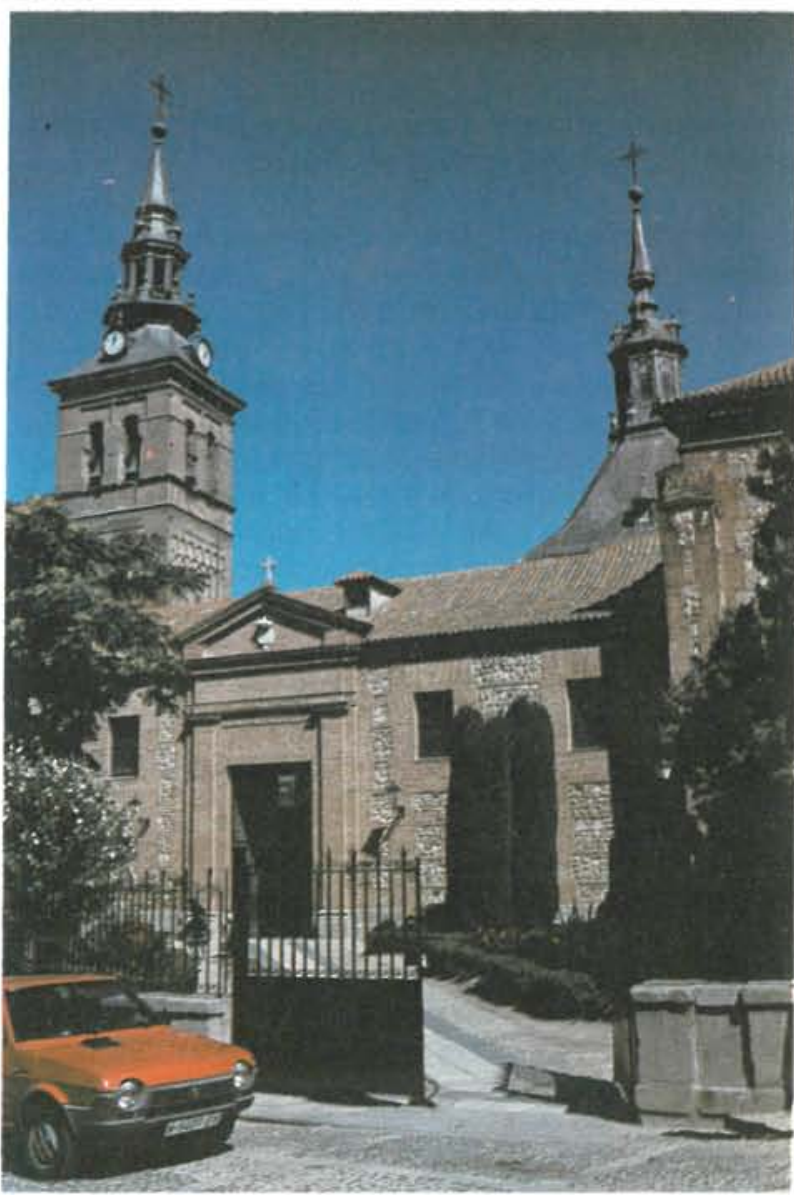

Iglesia de Navalcarnero. lo largo de la Historia ha ocupado eras, ágoras, calles, plazas, iglesias, salones cortesanos y recintos plebeyos, además de edificios específicamente construidos para él. Para que haya teatro únicamente son necesarios el Actor y el Público. El Actor puede ser una sola persona; el Público, como minimo consta de dos, según explica Vittorio Gassman en una pizarra, dibujando un triángulo que une esos tres puntos y que acaba convirtiéndose en la corona de Dios.

La manera de albergar las relaciones entre esos tres puntos, con sus múltiples variantes y condicionamientos, es el objeto de la Arquitectura Teatral. Independientemente del tamaño o de la categoria de un teatro, siempre habrá un Actor y siempre habrá un Público (para el primero el edificio será un lugar de trabajo, mientras que para el segundo lo será de esparcimiento), y siempre podrá exigirse al Arquitecto que facilite el trabajo, la diversión, el confort y la seguridad de los que ocupan su edificio.

Navalcarnero es una ciudad pequeña, y el Teatro Centro es un teatro pequeño; pero la problemática que plantea esta Rehabilitación no es esencialmente diferente a la de un teatro grande en una ciudad grande. Las zonas funcionales y los capitulos del equipamiento son los mismos para todos los teatros (en rigor faltaria en el de Navalcarnero una Sala de Ensayos); la diferencia estriba solamente en el tamaño de las zonas o en la cantidad y calidad de los equipamientos.

\section{La Ciudad}

Navalcarnero tiene actualmente unos 9.000 habitantes y está situada en el Suroeste de la provincia de Madrid, a $31 \mathrm{~km}$ de la capital. Fue fundada en 1500 como señorio del Rey y se consolidó rápidamente, contando con 2.000 habitantes a comienzos del siglo XVII. En los tiempos en que fue construido el Teatro Centro (finales del siglo pasado) su población era de unos 3.800 habitantes.

El núcleo urbano posee elementos de interés histórico-artístico, fundamentalmente la Iglesia (con sus espléndidos chapiteles) y la plaza de Segovia, además de algunas ermitas y casas blasonadas.

El teatro se encuentra muy próximo a la Iglesia y a la Plaza. Delante de él se extiende un amplio espacio abierto que se utiliza para el baile durante las fiestas; este espacio va a ser acondicionado como plaza pública, respetando su carácter y usos actuales. Contiguo al teatro existe un edificio de construcción reciente, también de propiedad municipal, que alberga una discoteca; este edificio carece de interés y se ha planteado su sustitución a medio plazo. 
Existen actualmente otros proyectos de recuperación de edificios y espacios públicos contiguos al teatro que mejorarán notablemente la calidad urbana del entorno.

\section{El Edificio}

El teatro de Navalcarnero fue construido por el Centro Obrero de la localidad. Actualmente el edificio es de propiedad municipal, pero en la denominación popular conserva todavia la referencia a sus creadores. La construcción es de ladrillo visto y constituye un sólido contenedor prácticamente ciego, excepto en su fachada principal.

Esta fachada, con su juego de huecos y remates y su tratamiento del ladrillo, tiene un innegable encanto dentro de su modestia, y evoca una arquitectura fabril que es tambièn una referencia a su origen. Es el elemento más potente y caracteristico del teatro, particularmente por el arco que remata los huecos superiores, que prefigura el arco de embocadura del escenario.

Probablemente por deber su origen a un Centro Obrero el teatro no respondió a la tipologia burguesa imperante en los tiempos en que fue construido. Si bien se mantuvo la secuencia clásica Vestibulo-Sala-Caja de Escena, las dimensiones y configuración de estos espacios se apartaron del modelo tradicional, resolviéndose con tres nitidos volúmenes paralelepipédicos de una contundente simplicidad.

El conjunto resultante no podia juzgarse proporcionado funcionalmente, ya que tanto el Vestibulo como la Caja de Escena resultaban pequeños con relación a la Sala; por otra parte la carencia absoluta de decoración y la pobreza de los acabados eran factores que no contribuian a una imagen atractiva del interior del teatro.

El edificio habia sufrido un número indeterminado de reformas, y su estado de conservación era bastante lamentable, exceptuando las fábricas de ladrillo. La cimentación estaba disgregada, las cubiertas (de uralita) presentaban numerosas roturas y goteras, carecia casi por completo de instalaciones y equipamiento y los acabados estaban muy deteriorados. Antes de la Rehabilitación el teatro era utilizado por una Asociación Cultural local que desarrollaba sus actividades en condiciones bastante precarias.

\section{La Rehabilitación}

La Rehabilitación Ilevada a cabo en el Teatro Centro se inscribe en el marco de la politica de recuperación de teatros públicos; en este caso ha sido subvencionada integramente por la Comunidad de Madrid, que firmará un convenio de uso con el Ayuntamiento de Navalcarnero, el cual continuará siendo propietario del edificio.
El planteamiento básico de esta Rehabilitación ha sido el respeto al edificio preexistente. Razones no sólo presupuestarias, sino también de sentido común, han aconsejado una intervención que, sin acometer transformaciones desproporcionadas, sirviera para dotar al teatro de un minimo de servicios y confort, asi como para asegurar la funcionalidad de los espacios destinados al público y a las representaciones.

Asi, pues, se ha tratado de llevar a cabo una obra que recuperara el teatro para su uso primitivo y lo hiciera válido para otros (cine, música), respetando casi integramente la estructura principal y las fachadas del edificio, pero interviniendo decididamente donde se ha considerado imprescindible.

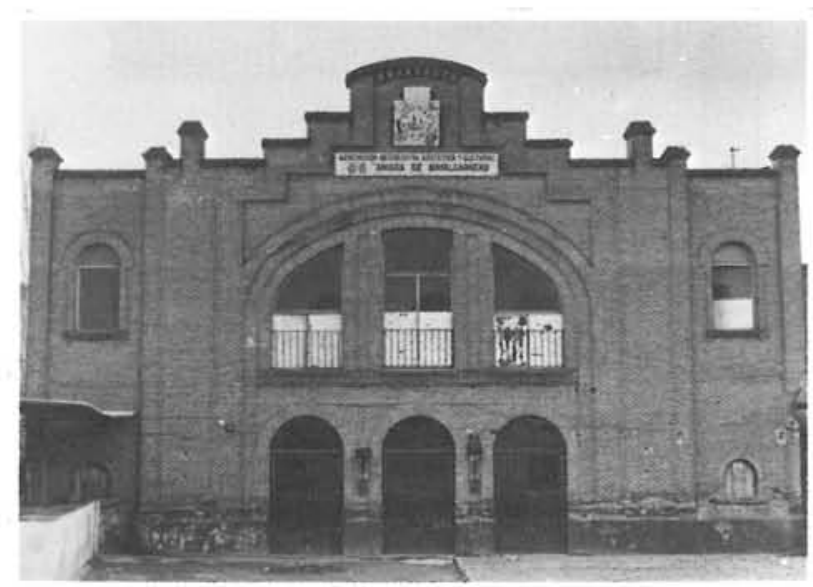

Fachada principal del Teatro Centro antes de la Rehabilitación.

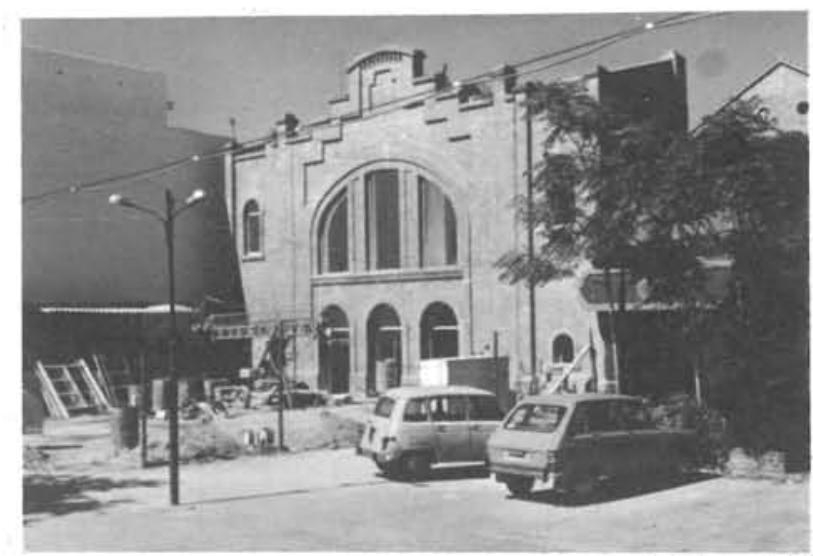

Vista del teatro, desde el espacio abierto que se extiende delante de él, durante las obras de Rehabilitación. A la izquierda, la gran medianeria que se pretende eliminar mediante un convenio con la propiedad. A la derecha, la entrada de la discoteca. 


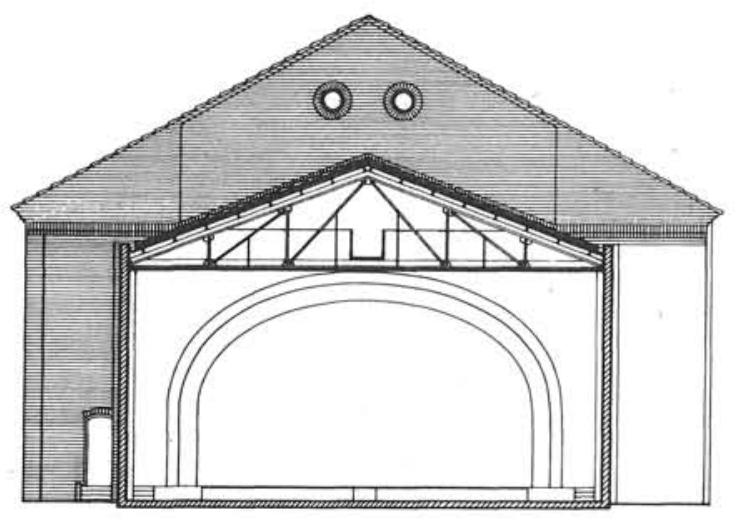

Sección transversal por sala.

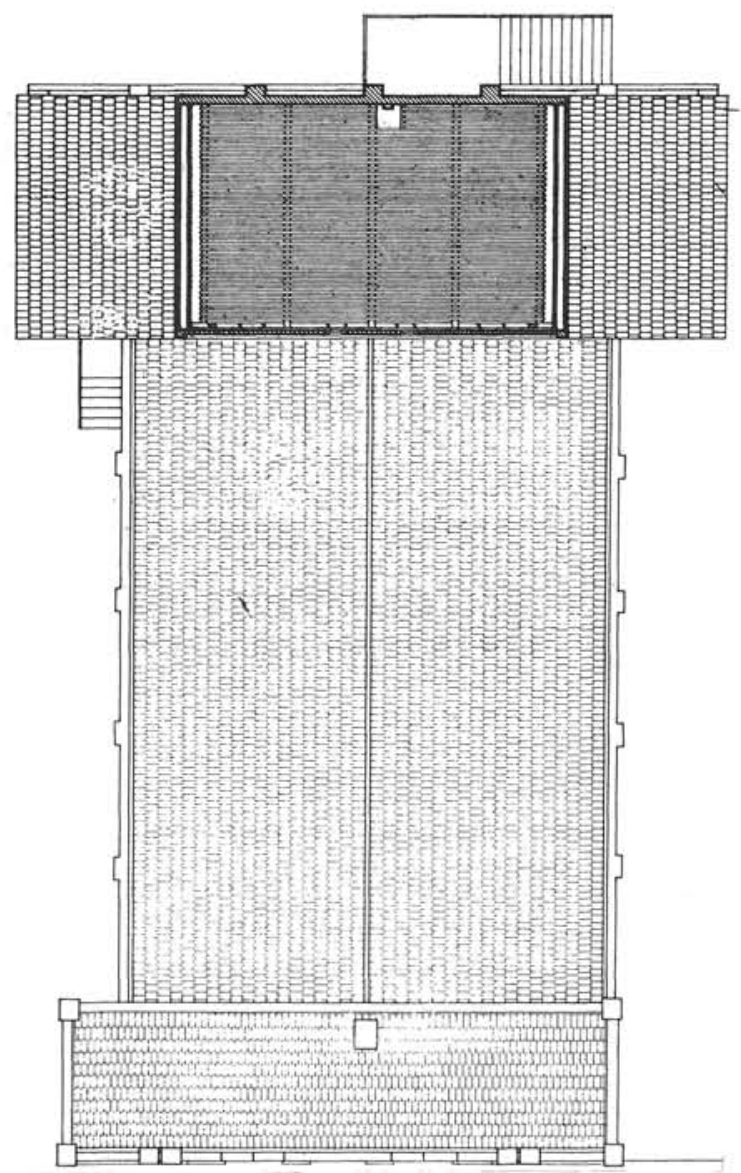

Planta de peine.

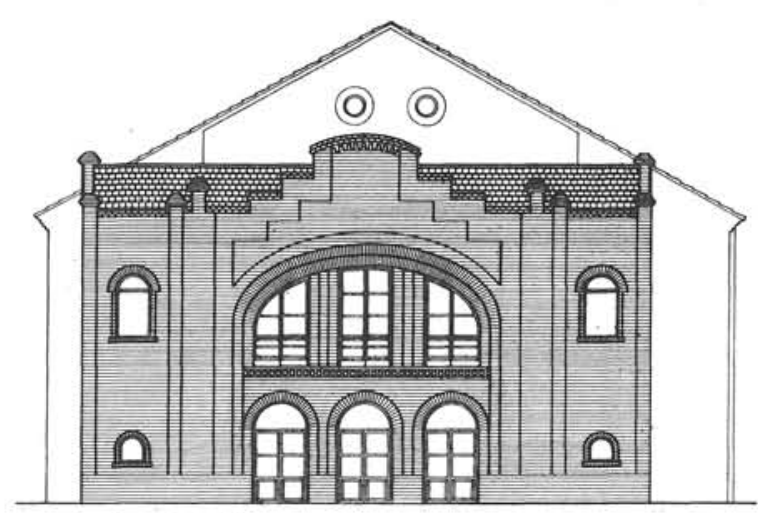

Alzado principal.

\section{LA ARQUITECTURA}

Se entiende aqui "Arquitectura" en su sentido más funcional, esto es, el conjunto de espacios y elementos que configuran el edificio, haciéndolo apto para el uso a que está destinado.

Las intervenciones que se han realizado en el Teatro Centro sobre el edificio preexistente se describen pormenorizadamente a continuación, según las distintas zonas funcionales. Al margen de estas intervenciones, se ha procedido a recalzar la mayoria de la cimentación, restaurar las fachadas y sustituir integramente las cubiertas (que se han resuelto con tablero aglomerado hidrófugo y teja plana), carpinterias, instalaciones, pavimentos y acabados del edificio.

El coste total de la obra civil realizada ha sido de unos 34 millones de pesetas, para una superficie construida de aproximadamente $1.000 \mathrm{~m}^{2}$.

\section{Caja de Escena}

La Caja de Escena del teatro tenia una altura de unos $7 \mathrm{~m}$, medidos desde el piso de escena hasta los tirantes de las cerchas metálicas que sustentaban la cubierta de uralita a cuatro aguas. Carecia de cualquier clase de Maquinaria Escénica y de posibilidad de colgar decorados y fo$\cos$, dadas la fragilidad e innacesibilidad de las cerchas (los muchachos de la Asociación Cultural que ocupaban el local colgaban sus rudimentarios telones de unos listones recibidos con yeso en las paredes del escenario). La escena estaba separada del foso, exceptuando una pequeña trampilla, por un forjado horizontal de hormigón sin pavimento alguno. No existia entrada de carga.

La intervención ha consistido en elevar la Caja de Escena, permitiendo la introducción de un peine visitable, demoler el forjado del piso de escena en la zona de actuación, crear una corbata, ampliando de paso el foso escénico, y abrir una entrada de carga.

Las correas de la nueva cubierta de la Caja de Escena se apoyan en dos hastiales elevados sobre los muros de fondo y embocadura, previo zunchado perimetral del conjunto. El hastial de fondo se ha construido continuando la fábrica de un pie de ladrillo existente, con sus contrafuertes, hasta el apoyo de la estructura de cubierta. Sobre el muro de embocadura se ha introducido una cercha metálica que carga en dos pilares también metálicos encastrados en el muro, para evitar solicitaciones excesivas del arco de embocadura. El hastial de este lado no es, pues, portante, y se ha construido de medio pie. Para estas operaciones se ha buscado un ladrillo que se pareciera lo más posible al existente, tratando de homogeneizar las fábricas antigua y nueva. 
En el hastial de embocadura, por encima del peine, se han abierto dos ojos de buey, uno de los cuales sirve para alojar un extractor de aire y el otro para proporcionar luz natural al peine y salida a la cubierta de la Sala para su mantenimiento.

El peine se ha formado con dos familias de vigas: la primera está constituida por 5 perfiles HEB 200 situados a intervalos de 2,50 m, que apoyan en el cordón inferior de la cercha de embocadura y en el hastial posterior de ladrillo. La segunda familia es la de los rastreles, paralelos a la embocadura, que son 40 vigas UPN 80 colocadas boca abajo a intervalos de $16 \mathrm{~cm}$. El peine queda situado a 10,50 m sobre el piso de escena, lo cual, teniendo en cuenta que la altura de trabajo de la boca (dadas las caracteristicas del arco de embocadura) será normalmente de unos $5 \mathrm{~m}$, es la altura minima exigible dentro de la modera- ción que se ha pretendido en la intervención. El ancho total del peine es de 10,20 m; se accede a él por una escalera de pates que parte de la galeria de fondo.

Esta galeria de fondo, colgada de la estructura del peine, une las dos galerias laterales, que son las cubiertas de los nuevos Camerinos, a las que se accede por dos escaleras situadas en los hombros del escenario.

Se ha mantenido el arco de embocadura al considerar que su demolición supondria una intervención desproporcionadamente agresiva con el edificio preexistente. Para paliar el problema del escaso fondo del escenario $(6,50 \mathrm{~m}$ entre paredes) se ha creado una corbata que avanza $2 \mathrm{~m}$ por delante del arco de embocadura, consiguiendo asi una profundidad de escenario, en el eje, de $9 \mathrm{~m}$.
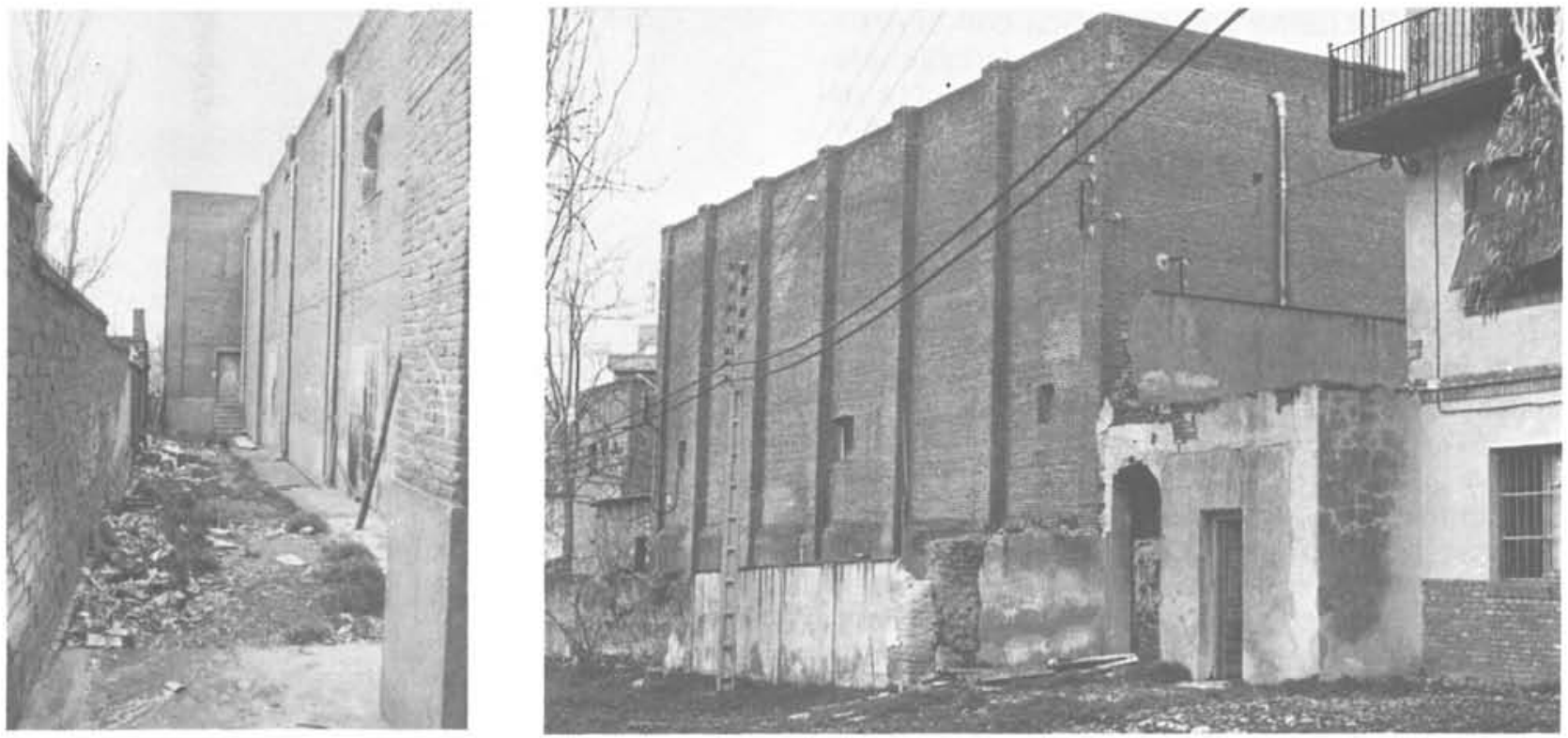

Fachadas lateral y posterior antes de la Rehabilitación
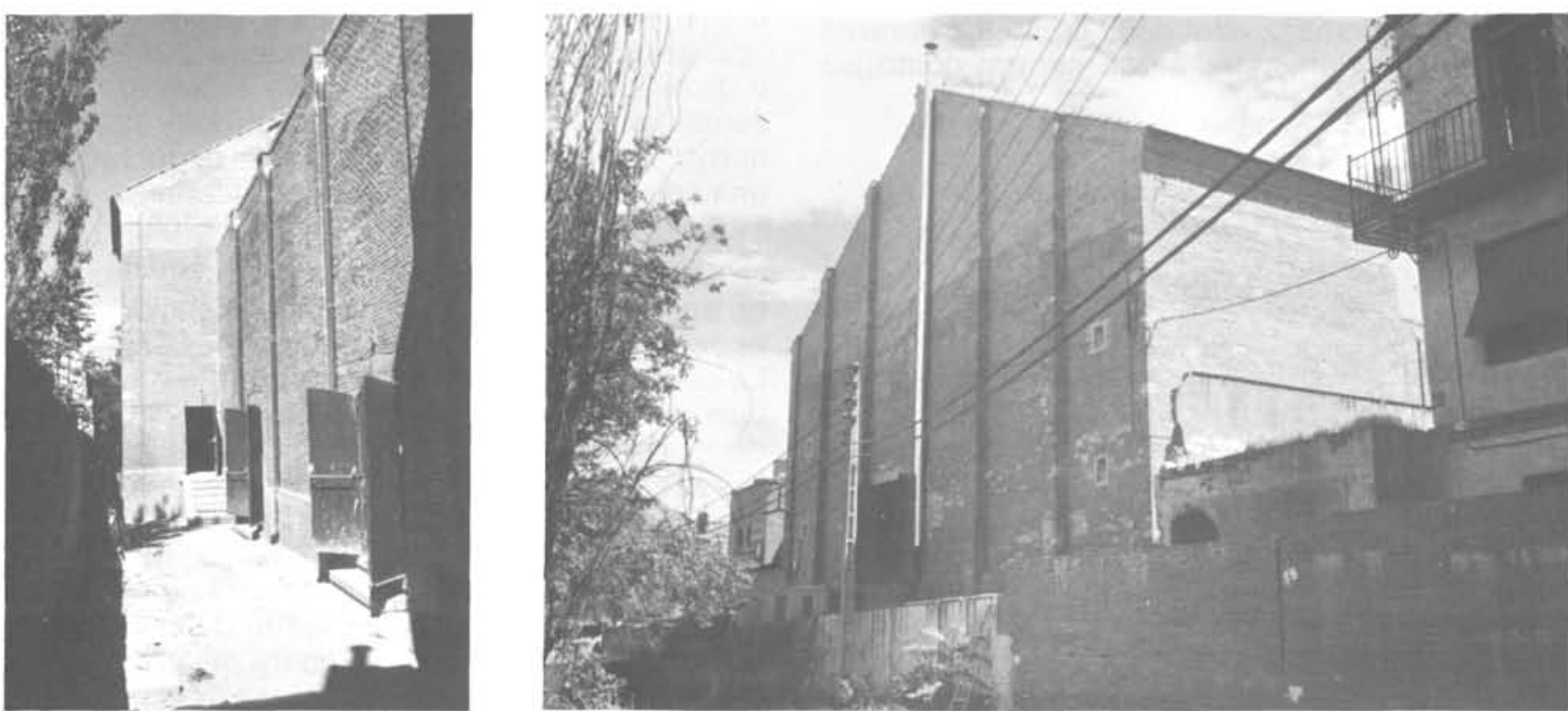

Fachadas lateral y posterior durante las obras. 
Esta corbata se aprovecha para ampliar el foso escénico, cuyo forjado de techo se ha demolido parcialmente, sustituyéndolo por un entablado que apoya sobre una ligera estructura metálica de carreras paralelas a la embocadura. Este entablado está formado por módulos practicables de $1 \times 1 \mathrm{~m}$, permitiendo asi crear escotillones en la zona de actuación. En la zona de corbata la estructura portante del entablado es también desmontable, para poder obtener un pequeño foso de orquesta si se quiere. La escalera de bajada al foso, que se ha conservado, aunque mejorada, queda tapada por un entablado abisagrado que permite pisar encima del hueco, a nivel de escena, cuando no tenga que usarse la escalera.

En el muro de fondo de la Caja de Escena se ha cegado una ventana que existia y se ha abierto una puerta de carga que comunica con el espacio trasero y, a través de éste, con la calle lateral. Lamentablemente, la diferencia de cota del nivel de escena con esta calle es de más de $5 \mathrm{~m}$, y ha sido imposible resolver este desnivel con una rampa debido a la excesiva inclinación que tendria ésta y a que descalzaria el edificio del teatro y el contiguo, creando nuevos problemas de cimentación. Se han construido, pues, dos escaleras para salvar esta diferencia de cota, contando con que para algunas cargas podrán utilizarse rampas provisionales de madera.

La superficie del escenario queda en $120 \mathrm{~m}^{2}$, la del foso escénico en $60 \mathrm{~m}^{2}$, y la del peine en 66 $\mathrm{m}^{2}$. Las paredes interiores de la Caja de Escena se han tratado con enfoscado y pintura (negra en el escenario y gris en el foso). El pavimento es de tarima de pino de $3 \mathrm{~cm}$ de grosor en el escenario, slurry en el foso y goma negra en las escaleras y galerias. Las instalaciones van vistas. La luz artificial es de tres tipos: blanca fuerte como luz de trabajo, azul débil como luz durante la representación, y lamparón central como luz de ensayo.

\section{Sala}

La Sala resultante de la Rehabilitación se configura en un patio de butacas, con capacidad para 290 espectadores, y un anfiteatro, con capacidad para otros 95 . El aforo total de la Sala es, pues, de 385 espectadores, manteniendo unos buenos estándares de seguridad y confort: 90 $\mathrm{cm}$ de distancia entre respaldos, $110 \mathrm{~cm}$ de ancho en pasillo central, 7 como número máximo de butacas servidas por un pasillo.

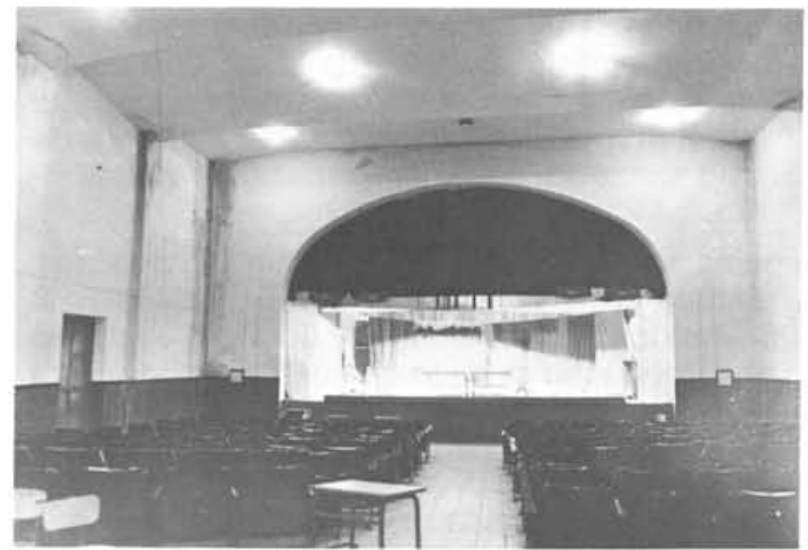

La Sala, desde la entrada, antes de la Rehabilitacion.

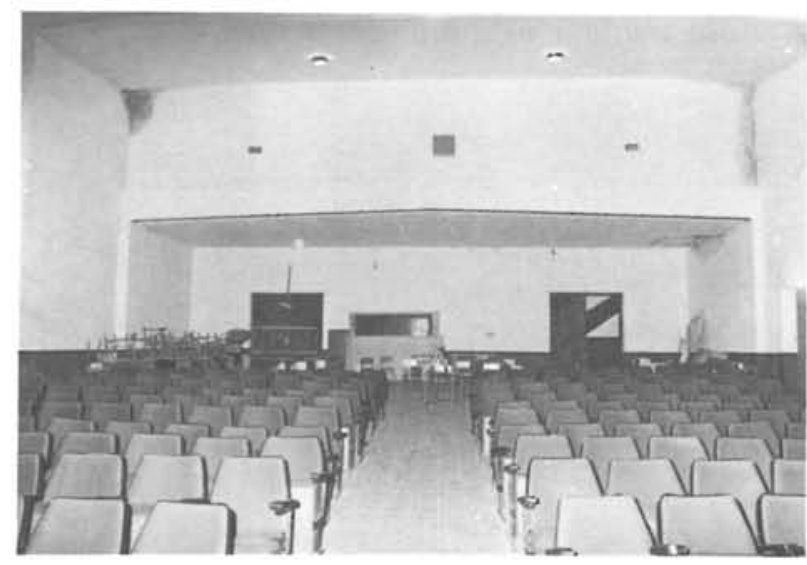

La Sala, desde el escenario, antes de la Rehabilitacion.

El patio de butacas resulta más corto que antes de la Rehabilitación, al haberse utilizado en planta baja la segunda crujia del edificio para el Vestibulo; en compensación se ha creado un anfiteatro en la planta alta de esta segunda crujia (que estaba ocupada por una pequeña biblioteca y otras dos salas), demoliendo el forjado horizontal preexistente y sustituyéndolo por uno nuevo, inclinado, que permite a los espectadores una correcta visibilidad sobre el escenario.

La Sala se ha tratado sobriamente por razones de austeridad y por no distraer la atención de los espectadores de lo que ocurra en el escenario. La disposición de las butacas en el patio es según circulos concéntricos, siguiendo la curvatura de la corbata, para favorecer la visibilidad y la sensación de colectividad del público; en el anfiteatro se han dispuesto filas paralelas al peto para aprovechar mejor el espacio disponible, pues aqui los objetivos anteriores ya estaban cubiertos. La pendiente del patio de butacas se ha corregido todo lo posible para mejorar la visibilidad, y se han mantenido las salidas de emergencia preexistentes. 


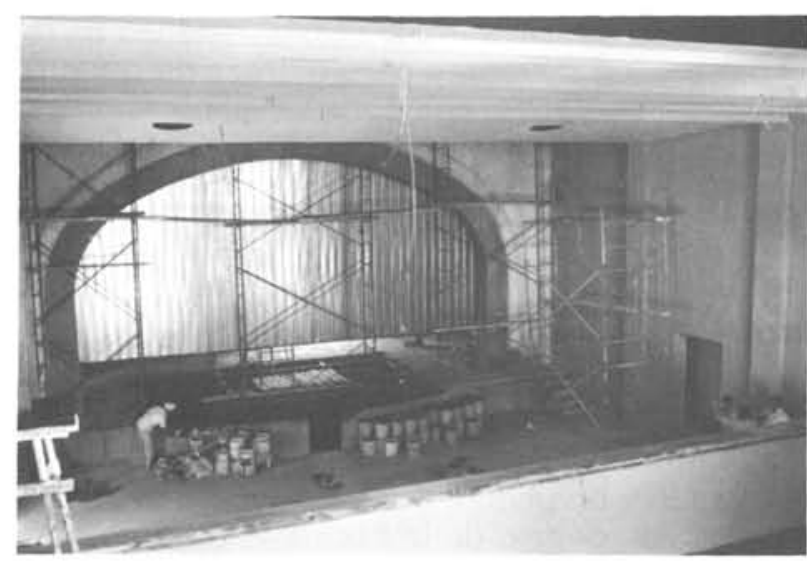

La Sala, desde el anfiteatro, durante las obras.

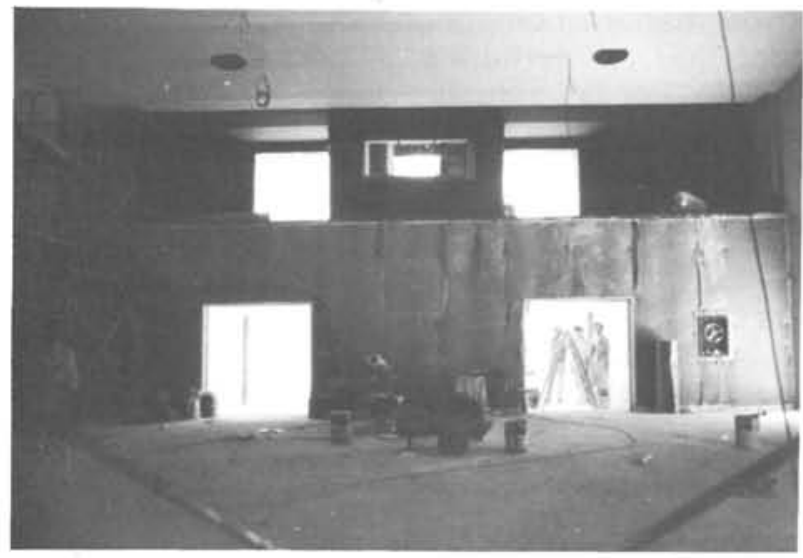

La Sala, desde el escenario, durante las obras.

El techo se ha diseñado para optimizar la respuesta acústica de la Sala, jugando con las inclinaciones y los resaltos de las diferentes placas de escayola que lo conforman para obtener las condiciones deseadas de reflexión y difusión. Este techo aloja un puente de luces, accesible desde la cabina de control, que queda oculto a la vista del público.

Las paredes laterales se han tratado con revoco pétreo sobre aislamiento térmico proyectado y son también reflejantes. Para evitar la generación de ecos múltiples, debido a esto y a su paralelismo, se han incorporado los grandes paneles de calefacción a las paredes laterales como elementos que rompan su continuidad.

Las paredes de fondo son absorbentes y se han tratado con entelado sobre manta de fibra de vidrio. Este entelado absorbente evita la devolución de ecos a la Sala y ayuda a conseguir el tiempo de reverberación óptimo, que queda en $0,8-0,9$ segundos a frecuencias medias.

Las dimensiones resultantes son: altura media de la Sala en el patio de butacas, 7 metros; en el anfiteatro, 3,50 m; ancho de la Sala, $14 \mathrm{~m}$; fondo del patio de butacas, $15 \mathrm{~m}$; fondo del anfiteatro, 4,5 m; distancia de la corbata a la última fila del anfiteatro, $18 \mathrm{~m}$. El volumen de la Sala es, pues, de unos $1.700 \mathrm{~m}^{3}$, lo cual supone $4,4 \mathrm{~m}^{3}$ por espectador.

El pavimento es de linóleo holandés color madera; aparte de esto, todos los elementos de la Sala se han tratado en rojos, grises y negro. La iluminación se ha dispuesto por apliques de pared en el anfiteatro, por globos suspendidos del techo en el patio de butacas y por focos dirigidos desde el puente de luces en la embocadura. La luz de Sala se regula desde la cabina de control.

\section{Vestíbulos}

El Vestibulo principal ocupaba solamente la planta baja de la primera crujia del edificio, de unos $4 \mathrm{~m}$ de luz. La ampliación de este Vestibulo era, pues, una obra absolutamente necesaria para poder obtener un ámbito de acceso y desahogo para el público minimamente digno y espacioso.

Esta ampliación se ha llevado a cabo a costa del patio de butacas, utilizando la planta baja de la segunda crujia. Para ello se ha sustituido el muro de carga preexistente por dos pilares circulares de hormigón armado que quedan en el centro del nuevo Vestibulo, cuya superficie resulta de unos $90 \mathrm{~m}^{2}$, lo cual supone 3,2 espectadores por $\mathrm{m}^{2}$. Se han incluido un pequeño banco y una cartelera entre las dos puertas de acceso al patio de butacas; la barra del bar queda enfrentada a la escalera, en la primera crujia.

El Vestibulo superior se ha reducido ligeramente como resultado de la introducción de la cabina de control. De todas formas su superficie queda en unos $30 \mathrm{~m}^{2}$, lo cual supone 3 espectadores por $\mathrm{m}^{2}$, un estándar incluso mejor que el anterior.

La escalera que une ambos Vestibulos, de 1,80 $\mathrm{m}$ de ancho, tiene 23 alturas de $17 \mathrm{~cm}$, con dos mesetas. El hecho de que haya una sola escalera, que está en contradicción con una interpretación literal del Reglamento de Espectáculos vigente, entra en la lógica del diseño posible y fue negociado con las autoridades competentes. La escalera preexistente, de $1,50 \mathrm{~m}$ de ancho, tenia 21 alturas de $18,6 \mathrm{~cm}$ y estaba situada en el mismo lugar, pero desembarcaba al revés que la nueva.

El pavimento es de mármol en rojo y crema, marcando las circulaciones de público. Las paredes se han tratado con aislamiento proyectado, enlucido de yeso y acabado de pintura en color crema; los techos horizontales son blancos. La carpinteria exterior es de madera barnizada y la interior de madera lacada en negro, como los pilares circulares. Los paneles de calefacción se 


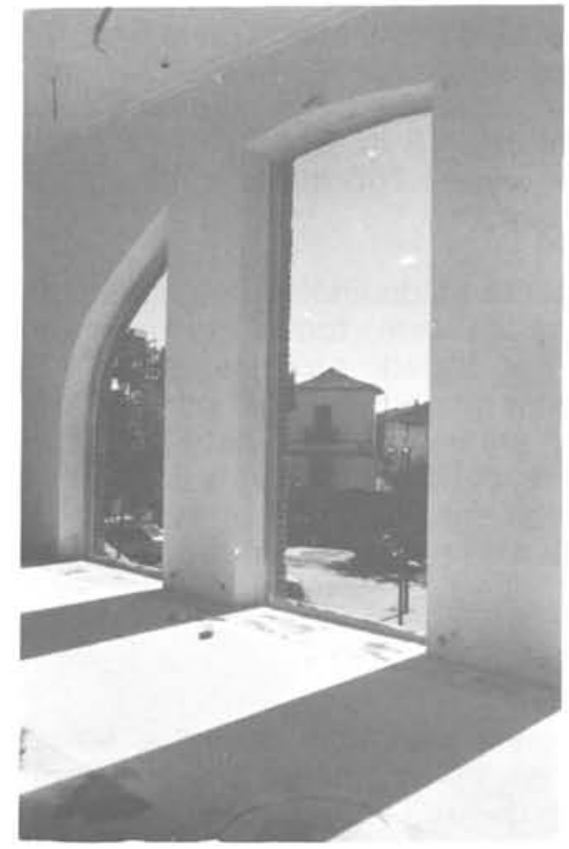

vestibulo superior durante las obıas.

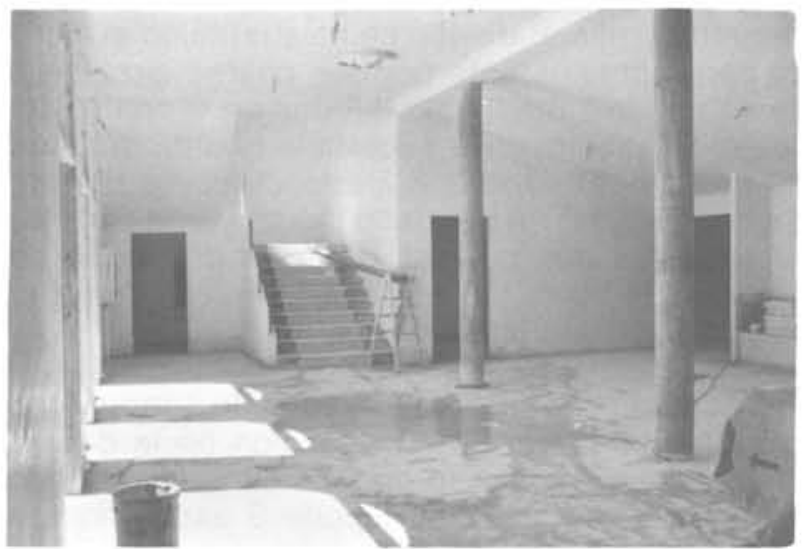

Vestibuio principal durante las obras.

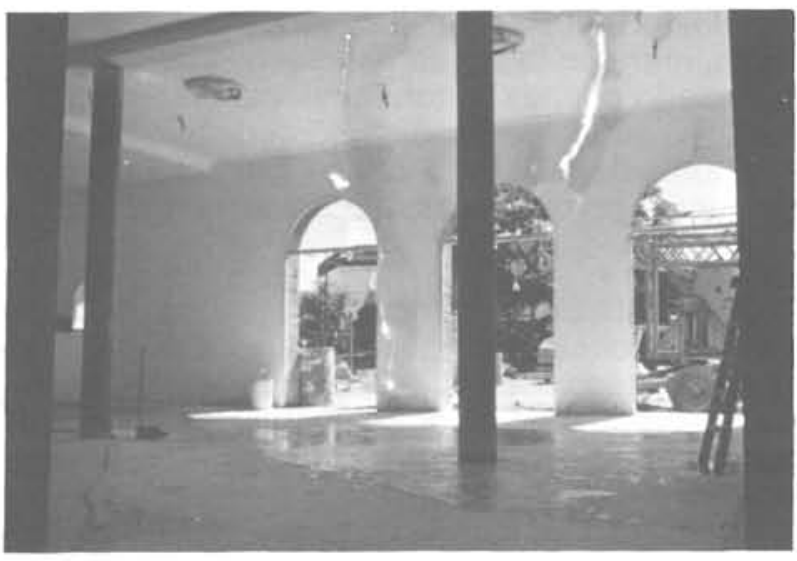

Vestibulo principal durante las obras. han pintado en rojo y la barandilla metálica de la escalera y los difusores para extracción de aire situados en el techo, en negro. La iluminación es por globos suspendidos de los techos, más unas linestras ocultas que iluminan la cartelera y el espejo situado tras la barra del bar.

\section{Servicios del Público}

Los Servicios que se ofrecen al Público son la taquilla, el bar y los aseos.

La taquilla y un pequeño almacén para el bar se han ubicado debajo de la escalera, para no hurtarle espacio al Vestibulo (la taquilla anterior también estaba en el mismo sitio). El bar consiste simplemente en una pequeña barra, situada en el lateral opuesto a la escalera, y se ha tratado de manera homogénea con el Vestibulo, de modo que no interfiera en la percepción espacial de éste. Por la ventanilla que queda junto a esta barra (simétrica a la de la taquilla en la fachada) puede organizarse el servicio de camareros si se instala una terraza en la futura plaza pública.

Los aseos se han ubicado simétricamente a ambos lados de la segunda crujia, bajo el anfiteatro, aprovechando la menor necesidad de altura libre de estos Servicios. Se han dispuesto 2 lavabos, 5 urinarios y 2 inodoros para los hombres y 2 lavabos y 5 inodoros para las mujeres. El pavimento es continuación del del Vestibulo, y las paredes se han revestido con alicatado blanco con algunos recuadros en negro. El aseo de hombres ventila mediante shunt y el de mujeres por una pequeña ventana, que enmarca los dos chapiteles de la iglesia de Navalcarnero.

\section{Oficina}

Se ha creado una pequeña Oficina (de unos 10 $\mathrm{m}^{2}$ ) con acceso desde el Vestibulo superior, en el lugar donde anteriormente estaban los aseos públicos. Esta Oficina servirá para albergar los servicios mínimos de administración y gestión del teatro. Se ha tratado de manera homogénea con los Vestibulos, aunque con el techo más bajo e incluyendo una estanteria de obra.

\section{Camerinos}

Los Camerinos que existian eran dos grupos de tres cuartitos situados en los hombros del escenario; solamente dos de ellos (los que daban a la fachada posterior) tenian ventilación. Las puertas abrian directamente al escenario.

La intervención ha consistido en crear cuatro Camerinos colectivos, construyendo una segunda planta sobre los preexistentes, retirando las puertas de los laterales del escenario y construyendo dos escaleras para el acceso a la segunda planta y a las galerias superiores. 


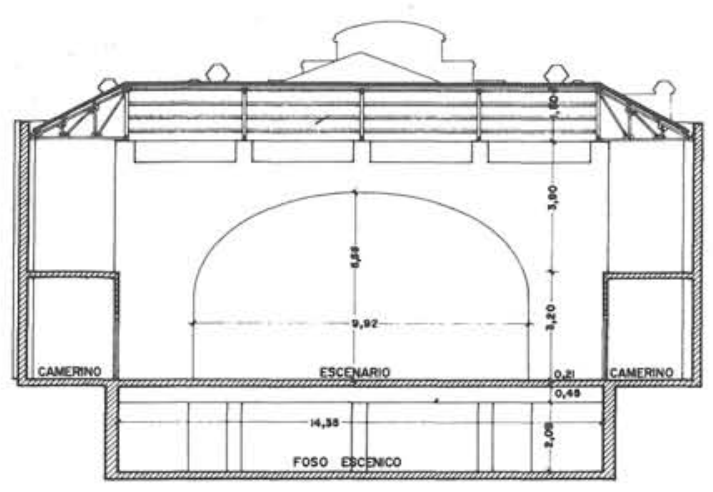

Sección transversal por el escenario antes de la Rehabilitación.

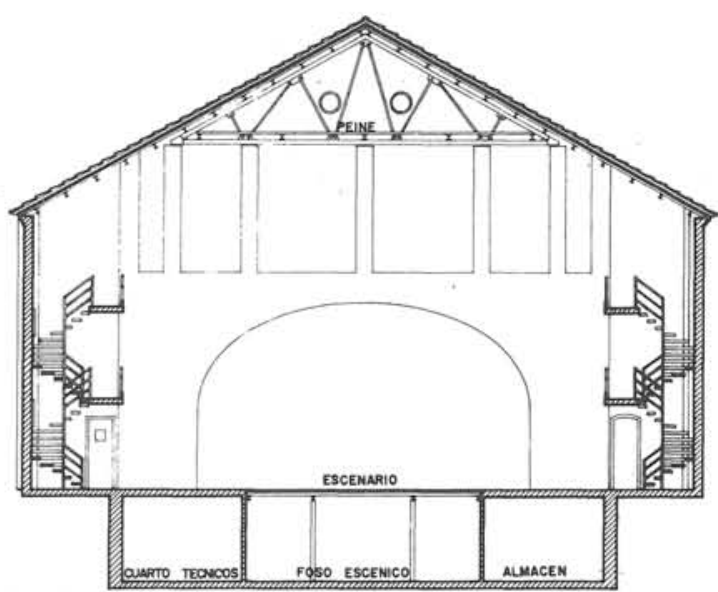

Sección transversal por el escenario después de la Rehabilitación.

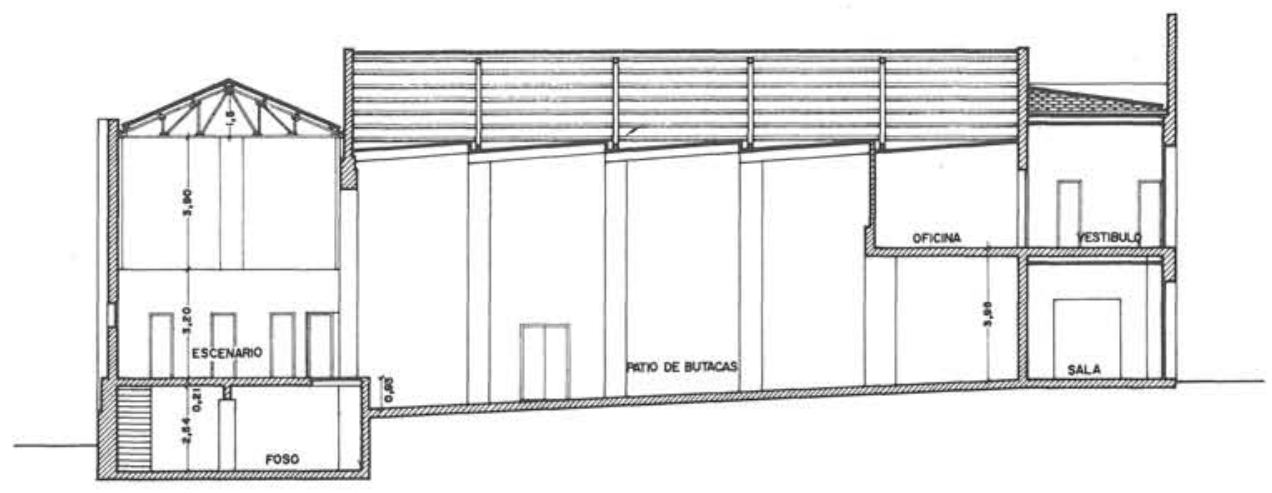

Sección longitudinal antes de la Rehabilitación.

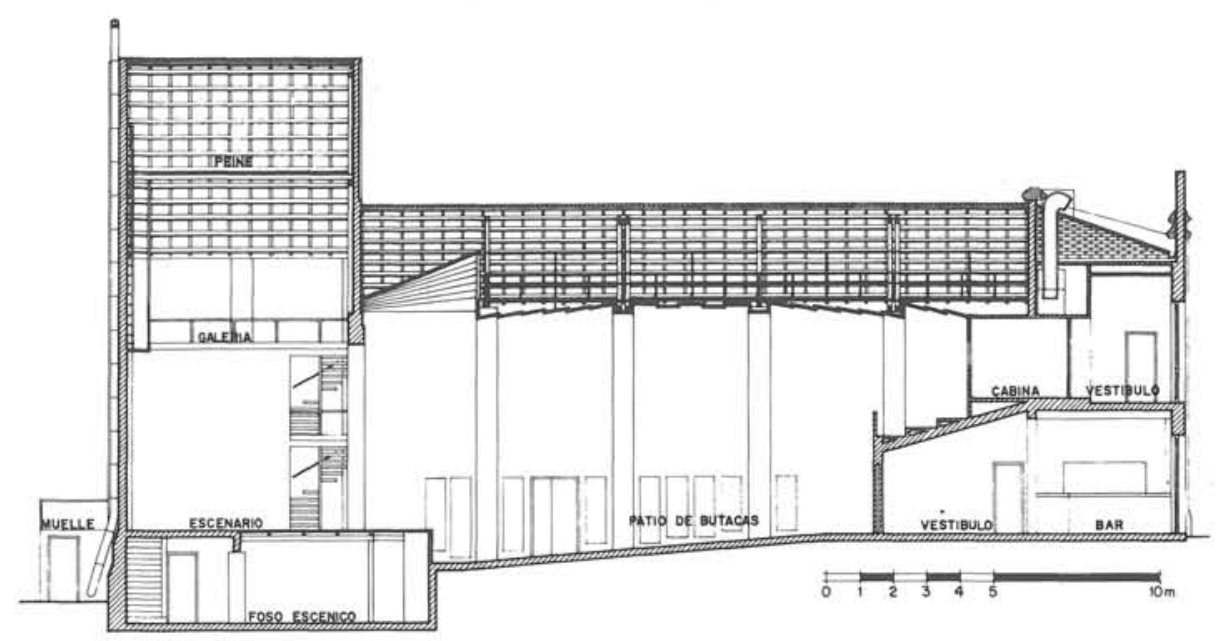


Los 4 Camerinos disponen asi de luz y ventilación naturales. En principio están destinados al uso de 4 personas cada uno, pero su superficie (12 $\mathrm{m}^{2}$ por Camerino) los hace aptos para ser ocupados por un número mayor de personas en caso de necesidad.

Existen, en cada Camerino, 4 puestos de maquillaje con luz perimetral, un lavabo, un espejo de cuerpo entero y barras y encimeras para colocar el vestuario y los efectos personales. El pavimento es de goma negra, como en las escaleras y galerias, las paredes se han tratado con alicatado blanco y corcho y los techos se han pintado de blanco.

\section{Locales Técnicos, Talleres y Almacenes}

La cabina de control se ha situado en el centro del anfiteatro, con el suelo recrecido con respecto al nivel del público para asegurar una correcta visibilidad sobre el escenario. En esta cabina (de unos $10 \mathrm{~m}^{2}$ ) se ubican el proyector cinematográfico y los controles de luz de Sala y de iluminación y sonido del espectáculo. El pavimento es de linóleo como el de la Sala; las paredes laterales y frontal están revestidos de corcho y el techo y la pared de fondo están pintados de negro.

Por una escalera de pates alojada en un armario dentro de la cabina se accede a un altillo situado sobre ésta, donde están ubicados los extractores de aire, y a través del cual se puede pasar al volumen comprendido entre el techo y la cubierta de la Sala. Atravesando este espacio se llega al puente de luces, situado paralelamente a la embocadura, donde se colocan los focos que iluminan el primer término del escenario.

En los dos laterales del foso escénico se ubican un Almacén (de $23 \mathrm{~m}^{2}$ ) y un cuarto de técnicos (de $19 \mathrm{~m}^{2}$ ), que también puede ser utilizado como pequeño Taller. El suelo de estas dependencias se ha tratado con slurry y las paredes con enfoscado y acabado con pintura gris. Las instalaciones van vistas.

\section{Instalaciones Generales}

Por razones de economia, las Instalaciones de Climatización se reducen a calefacción y ventilación forzada. El sistema de calefacción es convencional por agua caliente, con caldera para gasóleo C y radiadores de chapa de acero. El cuarto de caldera se ha ubicado fuera del volumen principal del edificio, para mayor seguridad, aprovechando su cubierta como pequeño muelle de carga para la entrada de decorados al escenario. Los radiadores son grandes paneles que han tratado de utilizarse como elementos decorativos. La extracción de aire viciado de la Sala y los Vestibulos se canaliza por conductos de Fi-

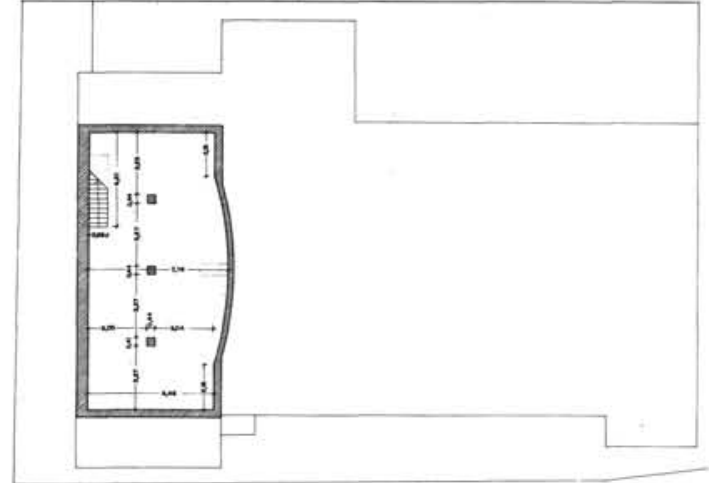

Planta de foso.

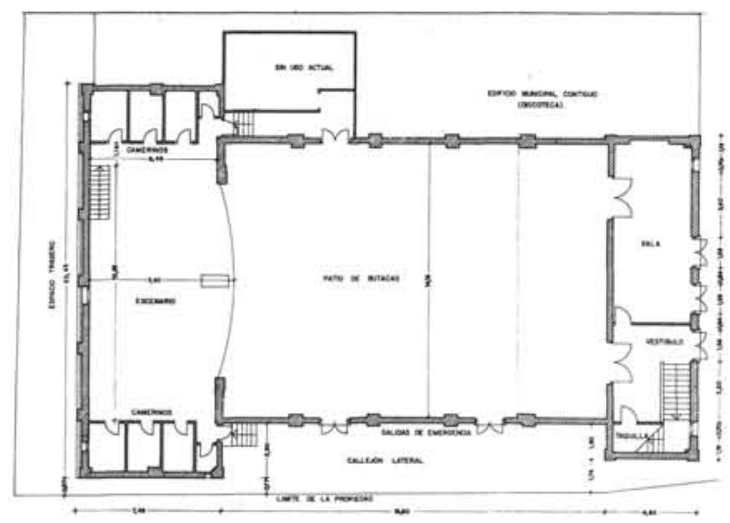

Planta baja.

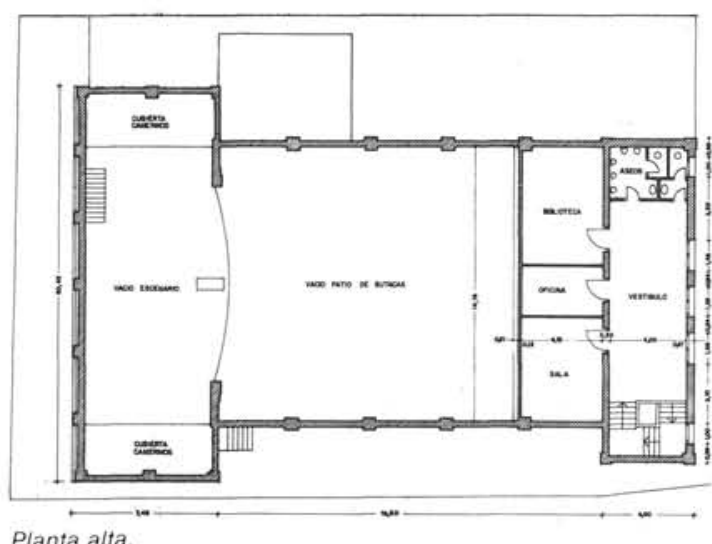

Planta alta.

$\Delta$

Arriba: Plantas del teatro antes de la Rehabilitación.

A la derecha: Plantas del teatro después de la Rehabilitación. 


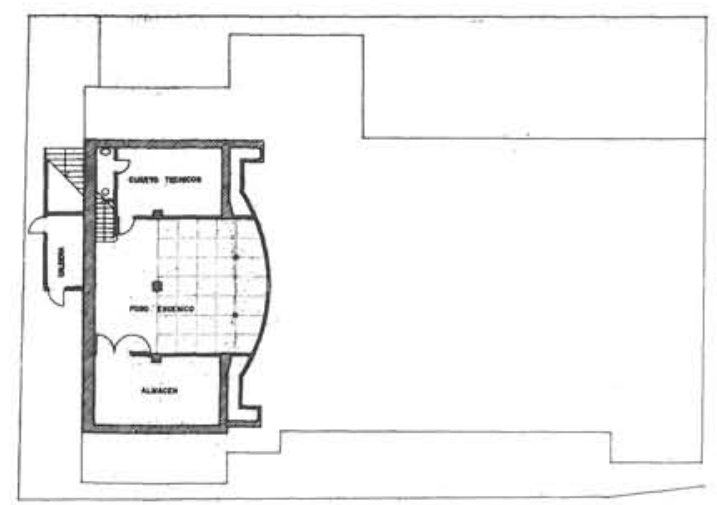

Planta de foso.

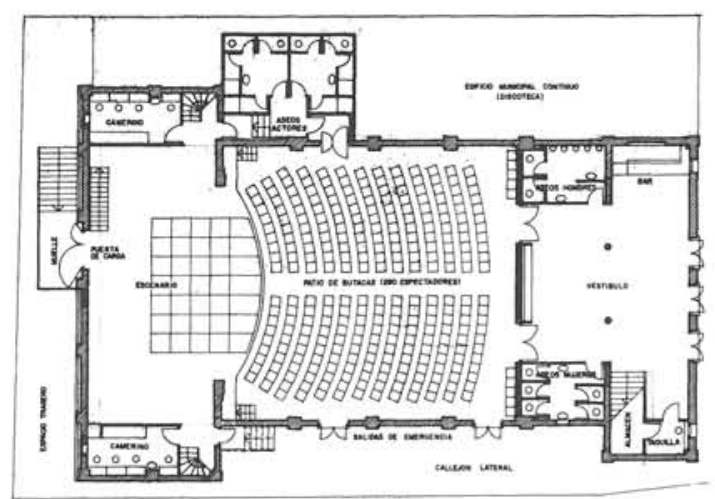

Planta baja.

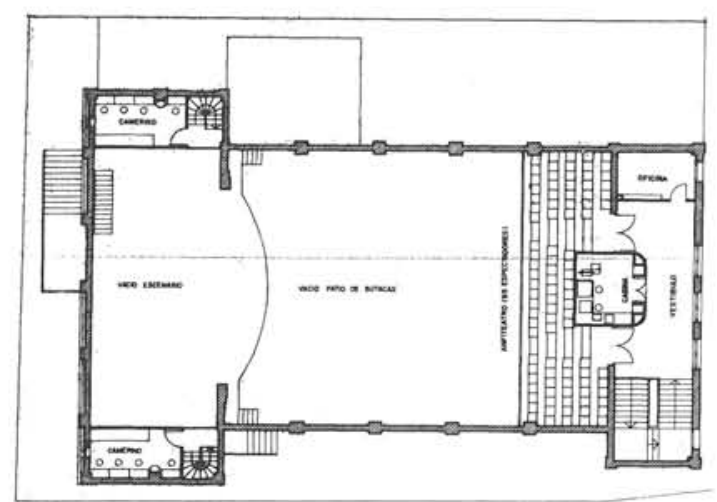

Planta alta.

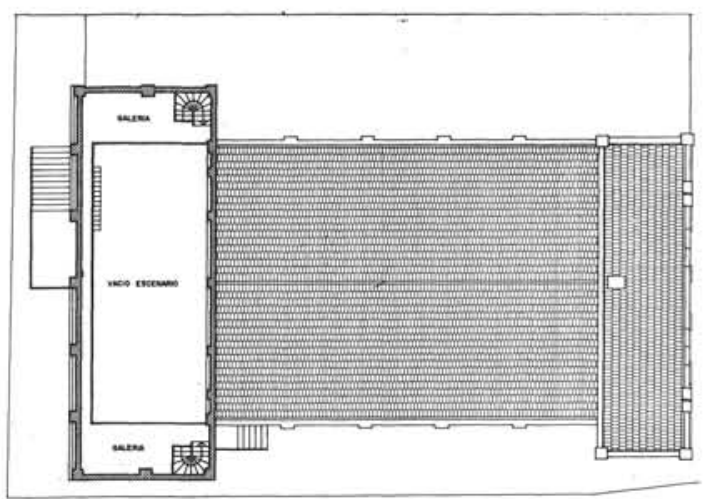

Planta de telar.
ber-Glass ocultos bajo los techos, ubicándose los extractores en el altillo de la cabina de control, desde donde el aire es expulsado al exterior a través de la cubierta de la primera crujia.

La Instalación de Electricidad no ofrece ninguna particularidad. Se ha contratado una potencia de suministro normal de $92 \mathrm{kw}$, más un suministro de socorro de otros 13,8 kw (15\% del anterior). La capacidad de los reguladores para la iluminación escénica es de $72 \mathrm{kw}$. El cuadro general de protección se sitúa en la taquilla, existiendo cuadros secundarios en el escenario, cuarto de caldera, cabina de control y bar.

La Instalación de Fontaneria proporciona agua fria y caliente (por medio de un calentador eléctrico) a los Camerinos y aseos de actores, y solamente fria a los aseos de público y al bar.

\section{Servicios del Personal}

Los aseos de actores se han situado en una zona sin uso preexistente que se adentra en el edificio contiguo (discoteca). Se han dispuesto dos bloques, para actores y actrices, contando cada bloque con un distribuidor con un lavabo, dos duchas y dos inodoros. El pavimento es de goma negra, las paredes se han alicatado en blanco con recuadros negros y los falsos techos de escayola se han pintado de blanco. La ventilación es forzada.

El cuarto de técnicos del foso puede servir como vestuario para éstos. Con acceso desde este cuarto, bajo la escalera del foso, se ha creado un pequeño aseo con ventilación directa a la fachada posterior del edificio.

\section{EL EQUIPAMIENTO}

Se entiende aqui "Equipamiento" como el conjunto de instalaciones y elementos que asegura el correcto funcionamiento del edificio como lugar de representaciones escénicas, y eventualmente de audiciones musicales y proyecciones cinematográficas. El Equipamiento asi entendido tiene una relativa independencia y movilidad con respecto a la "Arquitectura" del edificio: aunque debe estar fijado a la obra civil, las instalaciones y elementos que lo componen son susceptibles de ser trasladados o sustituidos sin necesidad de obras de gran envergadura.

En el Teatro Centro el Equipamiento se ha contratado directamente por administración, sin intervención de un Contratista general. El coste total ha sido de unos 17 millones de pesetas, que se han tratado de invertir según criterios de proporcionalidad, de manera que los niveles de calidad y cantidad fueran equivalentes entre los distintos capitulos y adecuados al tamaño y caracteristicas del Teatro y de la Ciudad. 
16

Informes de la Construcción, Vol. 38, n.o 380, mayo, 1986

\section{Protección contra Incendios}

El edificio ha sido dotado de todas las instalaciones especificas contra incendios que establece la correspondiente Norma Básica de la Edificación (NBE-CPI-82) para un Teatro de su aforo, esto es: a) Detección automática; b) Bocas de incendio; c) Extintores móviles; d) Sistemas fijos de extinción en escenario (por sprinklers) y en cabina de control (por halón); e) Pulsadores de alarma; f) Alerta; g) Alumbrado de emergencia; y h) Alumbrado de señalización.

Todas las puertas que cierran la Caja de Escena son resistentes al fuego y están dotadas de apertura anti-pánico. La embocadura del escenario se cierra con un telón de doble chapa de acero contrapesado y motorizado, que se utiliza también como bambalinón, y que puede descender sin aporte de energia. Las salidas de emergencia de la Sala están provistas también de apertura anti-pánico. En el diseño se han seguido las determinaciones de la normativa vigente al respecto, excepto en el caso de la escalera antes citada.

\section{Mobiliario}

Se han instalado butacas con estructura de chapa de acero laminado en frio, asiento y respaldo en espuma de poliéster, apoyabrazos de espuma integral y tapiceria acolchada desmontable de hilo ignifugo. Estas butacas tienen una separación entre ejes de $50 \mathrm{~cm}$ y van fijadas al suelo mediante tornillos.

El resto del mobiliario consiste simplemente en algunos muebles para la Oficina y sillas para la taquilla, la cabina de control y los Camerinos. Las encimeras para éstos se han construido solidarias a la obra de fábrica.

\section{Iluminación Escénica}

Se ha instalado un equipo de lluminación Escénica de $72 \mathrm{kw}$, situando los reguladores y el clavijero en el escenario (alojados en un armario empotrado en el hombro derecho) y la mesa de control en la cabina, por razones de economia. El sistema de iluminación consta de 7 barras para proyectores y una dotación de bases en el suelo del escenario.

Los reguladores (dimmers), que van incluidos en un rack de 19", son 3 de 24 kw/12 canales cada uno. La mesa de control tiene 36 canales y 24 preparaciones prefijadas por matriz. Los 64 proyectores instalados son de 1.000 watios, de tipo plano-convexo, panorama, recorte y PAR.

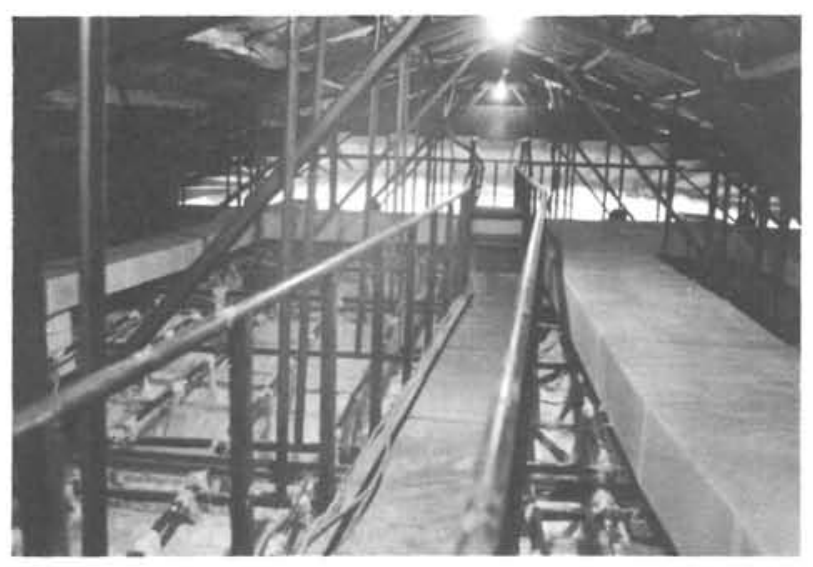

Pasarela bajo cubierta que conduce al puente de luces de la Sala (situado al fondo), durante las obras. Pueden apreciarse los conductos de extracción de aire viciado de la Sala y el entramado metálico, colgado de las cerchas, que soporta el falso techo de escayola de la Sala.

La primera barra va situada en el puente de luces de la Sala, a unos 8 metros de altura sobre el patio de butacas y a 4 metros de distancia de la embocadura. Las barras segunda, tercera y cuarta se cuelgan de varas del telar accionables mediante torno manual y no son fijas, aunque en principio se han dejado instaladas en unas posiciones convencionales. Las barras quinta y sexta son perpendiculares a la embocadura y están situadas en los hombros del escenario, adaptadas a las barandillas de las galerias de trabajo. La barra séptima está situada encima de la ventana de la cabina de control y sirve para la iluminación frontal de corbata.

Las barras 1.a, 3.a y 4.a llevan 12 bases para proyectores cada una; la barra 2.a, 16; y las barras 5.a, 6.a y 7.a, 8 bases cada una. Existen pues 76 bases en las barras. Además se han dejado 16 bases alojadas en el suelo del escenario, repartidas en hombros, fondo y corbata, lo cual da un total de 92 bases para proyectores. Estas bases son todas del tipo Schuko. Las distintas multipares terminan también en clavijas Schuko para su conexión al clavijero; éste se conecta a su vez a los reguladores mediante mangueras con multiconectores Harting. Desde los reguladores a la mesa de control va la manguera de señal. 

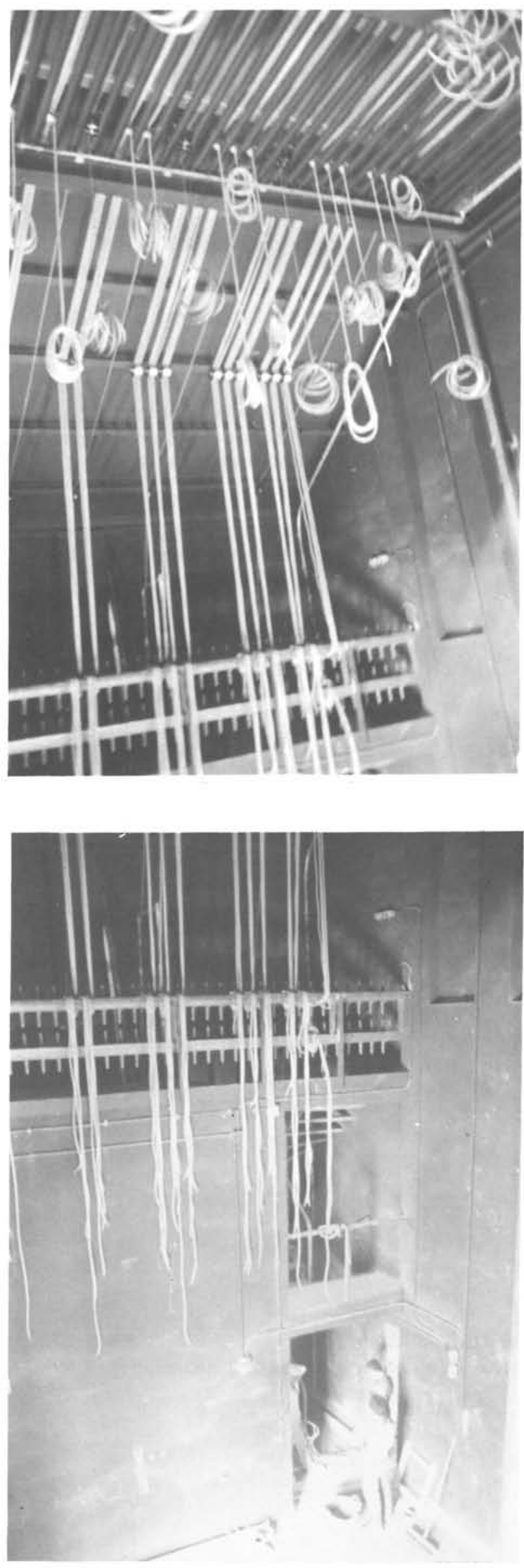

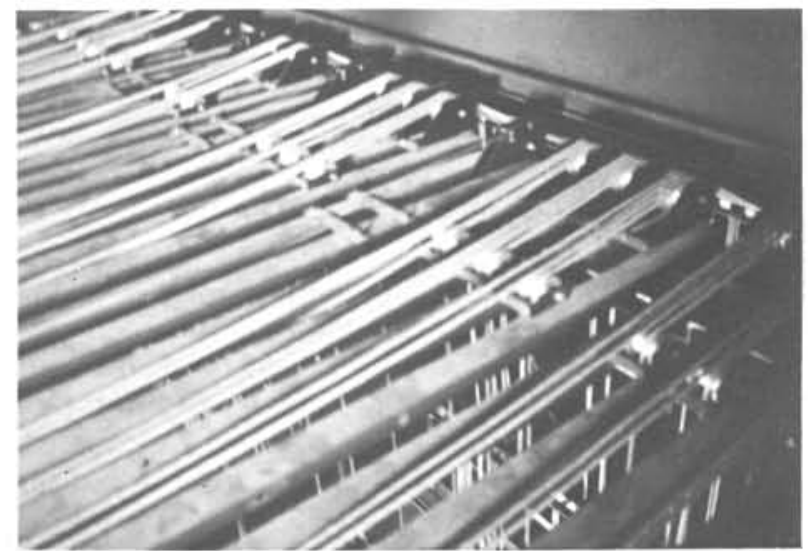

Cortes manuales y asistidos por torno manual durante su instalación en el teatro (faltan las varas). Pueden apreciarse la doble hilera de aspas de atado en la barandilla de la galeria de trabajo, los desvios para la adaptación al perfil de la cubierta y los desembarcos en el borde izquierdo del peine.

\section{Maquinaria Escénica}

Se han instalado dos tipos de cortes: de maniobra manual y de torno manual. Todos los carretes y poleas, incluidos los necesarios desvios (dado el perfil de la cubierta), son removibles, al estar fijados a la estructura metálica mediante bridas. Los cortes se manejan desde la galeria de trabajo del hombro izquierdo.

Los cortes manuales instalados son 15, cada uno con 4 tiros de maromillo de cáñamo que se atan al doble sistema de aspas fijado a la barandilla de la galeria. Estos cortes se utilizan para las bambalinas y elementos de decorado de poco peso.

Los 5 cortes cuyas varas cargan más peso (barras de focos, pantalla de proyección y telón de fondo) se manejan por tornos manuales desplazables a lo largo de una viga soporte. Los 4 tiros de cable de acero de cada corte se unen en uno solo, que es el que enrolla el torno mural.

Como mecanismos aparte de los cortes del peine se han instalado uno, contrapesado, para el telón de boca (de guillotina) y otro, con motor eléctrico, para la cortina americana. 


\section{Equipo de Sonido}

El Equipo de Sonido, al margen de la instalación propiamente dicha, consiste en: a) cinco fuentes de señal: un magnetófono, una platina, un plato y dos micrófonos; b) un cajetin de escenario para tomas de microfonia y fuentes de audio; c) una mesa de mezclas de 14 canales de entrada (2 estéreo), con etapa de potencia incorporada; y d) dos cajas acústicas de 250 w RMS instaladas a ambos lados de la embocadura del escenario. El control se situá en la cabina.

\section{Vestido de Escenario}

Los elementos de Vestido de Escenario instalados son: a) el telón de boca, de guillotina, en terciopelo acrilico rojo tableado, con fleco; b) una cortina americana de dos piezas, en otomán negro de canutillo fino; y c) una cámara escénica en otomán negro de canutillo fino formada por un telón de fondo, tres bambalinas y tres pares de patas. Como bambalinón se utiliza el telón de seguridad. Se ha renunciado a incluir un ciclorama dadas las reducidas dimensiones del escenario.

\section{Proyección Cinematográfica}

El equipo de Proyección Cinematográfica instalado es de fabricación española y sus elementos son: a) el proyector, situado en la cabina de control; b) el rectificador para alimentación de la lámpara, que va alojado en un armario empotrado dentro de la cabina; c) la lámpara de xenón, de $1.600 \mathrm{w}$; d) la linterna para la lámpara; e) las bobinas, de $3.600 \mathrm{~m}$; f) los objetivos (normal y Scope); y g) otros accesorios (bobinador, empalmadora, etc.). El sonido se canaliza a través del Equipo de Sonido del teatro, mediante un previo óptico.

La pantalla, de $8 \times 3,40 \mathrm{~m}$, va montada sobre un bastidor de tubo metálico que cuelga de una de las varas accionadas por torno, para poder escamotearla en el telar cuando no se utilice.

\section{Equipamientos Varios}

Se han incluido en este capitulo los siguientes equipamientos: los cortinajes de las puertas de Sala, la instalación de intercomunicación y megafonia, la señalización del edificio y una escalera extensible para el escenario.
Los cortinajes son de terciopelo acrilico ignifugo de color rojo, con pasamanos de nappel.

La instalación de intercomunicación comprende una central en el puesto del regidor, con estaciones auxiliares en la cabina de control y en la galeria de trabajo, y un sistema de avisos en Camerinos. La megafonia permite los avisos en los Vestibulos y en la Oficina.

La señalización se ha realizado en serigrafia, sobre soporte de chapa metálica en la fachada y sobre metacrilato en el interior del edificio.

La escalera extensible es de aluminio aleado y tiene una altura, en tijera, de $6,40 \mathrm{~m}$ (con tramo aéreo), y de $9,90 \mathrm{~m}$ como escalera de apoyo.

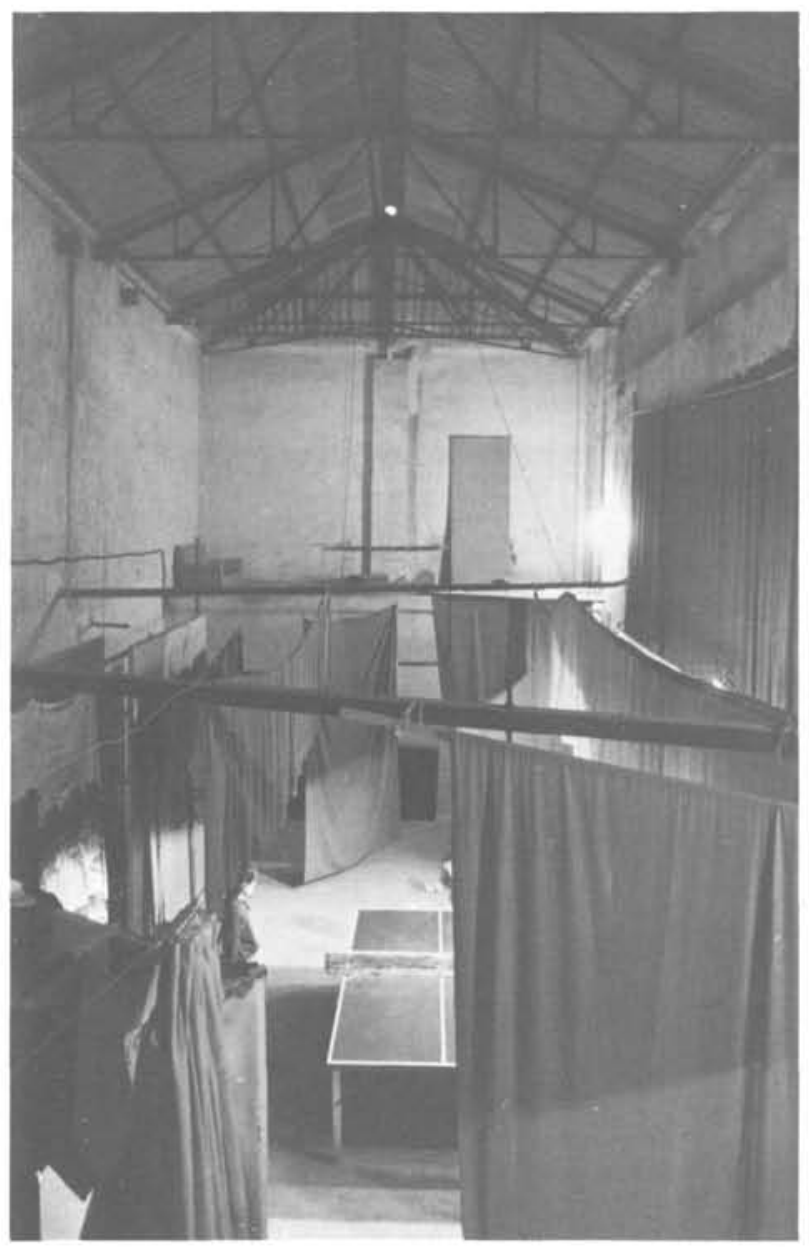

El escenario del Teatro Centro antes de la Rehabilitación. 